\title{
A Study of Network Negative News Based on Behavioral Finance Analysis of Abnormal Fluctuation of Stock Price
}

\author{
Cheng Chung Wu $\mathbb{D}^{1},{ }^{1}$ Ye Yan $\mathbb{D}^{1},{ }^{1}$ Tiantong Yuan, ${ }^{2}$ Chih Chiang Huang, ${ }^{3}$ and Ya Ju Tsai ${ }^{4}$ \\ ${ }^{1}$ School of Modern Finance, Jiaxing Nanhu University, Jiaxing, Zhejiang, China \\ ${ }^{2}$ School of Business Administration International College, Krirk University, Bangkok, Thailand \\ ${ }^{3}$ School of Business Administration, Cheng Shiu University, Kaohsiung, Taiwan \\ ${ }^{4}$ School of Public Finance and Taxation, National Kaohsiung University of Science and Technology, Kaohsiung, Taiwan \\ Correspondence should be addressed to Ye Yan; 425188447@qq.com
}

Received 1 October 2021; Revised 5 November 2021; Accepted 6 November 2021; Published 28 January 2022

Academic Editor: Daqing Gong

Copyright (C) 2022 Cheng Chung Wu et al. This is an open access article distributed under the Creative Commons Attribution License, which permits unrestricted use, distribution, and reproduction in any medium, provided the original work is properly cited.

\begin{abstract}
This article studies the model of the impact of real negative news on stock prices and provides evidence using China's A-share listed companies as an example. It first defines the negative news of the network. Then, it constructs the negative news to the stock price influence model, from the perspective of the theory of behavioral finance, the relationship between stock market and investor sentiment is systematically analyzed, and the theoretical support for the research of this paper is provided according to the definition of network negative news concept using the event study, abnormal returns test, regression analysis of the sample selected out of the study, observation of negative news before and after the abnormal returns, and excess returns changes. Studies have shown that negative news before 1 day and after 4 days makes stock price volatility larger, resulting in excess returns. The network negative news on the listed company's stock price fluctuations can cause a certain degree of impact; in the short term, the fluctuation of the stock price of listed companies is more active. This article finds that when online media disclose negative information on listed companies from one day before to four days later, stock prices will fluctuate greatly, generate excess returns, and continue to make stock fluctuations more active in the short term. In addition, when studying the influencing factors of the stock price fluctuations of listed companies, we found that stock price fluctuations are affected by the company's performance. The better the company's performance is, the smaller the stock price fluctuations will be when it is affected by negative news. Finally, we find that the higher the shareholding ratio of institutional investors in listed companies, the more stable the stock price.
\end{abstract}

\section{Introduction}

With the rapid rise of online media, online news and public opinion have attracted more and more attention from netizens. Each netizen is not only an audience of many online media but also a disseminator and creator of information. In an increasingly diversified media environment, according to the analysis of the public's psychological factors, netizens are more inclined to be exposed to conflicting, irritating, and ambiguous negative information; especially in today's rapid development of the mobile Internet, people's timeliness of obtaining information and the convenience are higher, and the negative news on the Internet is getting more attention.
With the continuous improvement of my country's capital market and the gradual improvement of residents' living standards, when people have surplus funds, most people will begin to invest, and the frenzy of "all people's stock speculation" will unfold, making my country's capital market activity greatly increased. However, most investors often lack professional knowledge, have immature investment attitudes, coupled with information asymmetry and herding effect, and easily fall into investment misunderstandings. With the increasingly complete market-oriented management of Internet media and the promotion of democratic politics, negative Internet news has developed rapidly as an unstoppable force, impacting the traditional communication concept based on positive reports. The 
purpose of online media to disclose negative information about listed companies is, first, to provide assistance to create a good market economy environment; second, to protect the interests of small and medium investors; and third, to inspire better and healthier listed companies' development. But, everything has two sides, and the disclosure of negative information about listed companies will also have an impact that cannot be underestimated: on the one hand, it will affect the reputation of listed companies to varying degrees, causing people to lose confidence in their brands, etc., thereby indirectly affecting company performance; on the other hand, it will cause investors and investment institutions to generate various investment sentiments, thereby affecting stock prices. The rise of network communication has brought great progress of mankind, especially in the field of information communication. It has incomparable advantages and provides many conveniences for people's life and economic development. However, at the same time, the negative effect of network communication can not be ignored, and it is easy to cause panic among investors in the stock market because of the negative effect of network media. Starting from the negative effect of network media, this study better analyzes the positive function of stock price volatility and urges investors to spread better news through the network system.

The occurrence of negative online news is often destructive to the listed companies and investors involved. It can be understood from behavioral finance that investors' behavior and decision making are generally easily affected by investment sentiment, and irrational investors are not a minority in my country's securities market. When a listed company has negative news and is widely concerned about and spread, investors will have negative emotions such as panic and anxiety, which will lead to them making wrong investment decisions under irrational circumstances. How to deal with the impact of negative news on the company is also a huge challenge for listed companies. Based on the current general environment of China's securities market, this paper studies the impact of real negative news spread by major online media on the stock prices of the companies involved. The significance of the research is mainly summarized as follows:

(1) From a practical point of view, Narayan [1] handcollected time-series data on positive and negative oil price news from 100 news sources from around the world, covering 59,129 news articles on oil prices. Using time-series predictive regression models estimated at 45 countries, it was shown that positive and negative news predict stock returns for at most 12 countries for which the oil price does not predict returns. When negative news occurs, it will affect listed companies and investors to varying degrees. The research in this article will provide effective solutions to investors and listed companies to deal with emergencies in this regard. Suggestions and measures: under the market economy, the stock price of listed companies may be affected by many factors, among which the network negative news is an important factor. Investors are increasingly relying on the public opinion information obtained on the network to assist their investment decisions; especially, the stock price fluctuations caused by public opinions in emergencies become more and more obvious. Based on the network negative news and stock price abnormal fluctuation theory concept, using the event study method and multiple regression method, the empirical study explores the emergency network negative news on the influence of the listed company's stock prices and analyzes the listed companies and the main reasons for the network negative news impact on stock prices and investors in the network negative news management measures.

(2) In terms of academic significance, Schumaker and Maida [2] investigated stock price movements within the minutes following financial news releases, broken down by media outlet, time of release, and article sentiment. They found that articles released through WSJ, Reuters-UK Focus, NYT, and FT all experienced significant positive returns, whereas articles in Barrons, MarketWatch, Forbes, and Bloomberg experienced significant negative returns. They found that articles released at certain times had abnormally high price movements associated with them, more so than random chance. Lastly, we discovered a minority of positive news articles trending upwards and suddenly reversing direction following a financial news article release. In one particular case, there was a period of several days where the release of IBM articles triggered large price declines with steady prices otherwise. They believe these findings could be used by companies as a form of stock price management. The research of this article can verify whether the negative news on the Internet will impact the stock prices of related listed companies and what factors of listed companies will cause different degrees of stock price changes. In the past, relevant scholars used to simply analyze the number and headlines of news, which made the research results have less practical value. The stock market is a mutual game market formed by the interaction of fundamentals, information, and capital. In this paper, from the perspective of behavioral finance, event research and multiple regression analysis are used to study the influence factors of hearsay and the stock price after hearsay. Due to the short development history of China's stock market, the investor structure is still dominated by small- and medium-sized retail investors. Due to the limitations of their professional knowledge, the investment decisions of small and medium-sized retail investors still mainly rely on the information circulating in the market. Moreover, due to the irrationality of investors, seemingly one piece of information can often bring a great impact to the market. 


\section{Review of the Literature}

2.1. Definition of the Concept of Network Negative News. In the news of media report, the different effects of news on all aspects can be divided into positive and negative ones. Compared with positive news, negative news has a negative state; it may be more difficult to control its effect in all aspects of transmission. Wei [3] defined the concept of negative news in his study of negative news information: negative news information refers to the negative change in the original fact state. The value of negative news information itself is negative, but not all negative news information will have a negative impact, and it may also have a positive effect. He [4] concluded the definition by summarizing and sorting out the relevant literature of negative information in the research of negative information: on the one hand, the reported content of news is a negative fact, which will have a negative impact; on the other hand, it is a nonnegative news fact, but it may be caused by the improper way of expression. But, generally speaking, it is mainly aimed at the real news events rather than personal opinions or public opinions. Bai and Chen [5] analyzed the definition of negative information in the concept of "negative information." Negative information refers to information, reports, and news that are not beneficial to the company or other relevant departments, highly dependent on news facts, and is real rather than rumor or unconfirmed information. As the name implies, the negative news on the Internet refers to the real and effective negative news released and spread through the Internet media, which will have negative or bad influence in a certain range.

The network negative news in this paper mainly refers to the negative news information of listed companies that has been officially confirmed in the financial market. This information comes from various financial websites or official websites, and such information may affect the stock price of the company. In the process of using information, accounting for the total number of investors in China stock market with the most individual investors, due to the structural weakness of their own knowledge and psychological factors such as cognitive biases, information access is relatively single, information analysis ability is limited, investors often see listed companies to disclose some important news, and once this news release, will quickly spread in the network media. Whether the information contained in the news is good or bad, it will influence investors' investment decisions intentionally or unintentionally, thus leading to the stock market volatility. Moreover, the fluctuating state of the stock market will be transmitted to the stock market participants in the form of information through the news media, and the stock market participants will change their investment decisions according to the information obtained. Especially with the popularization of the network, more people use the Internet to obtain information, which makes the influence of Internet financial news stronger and wider. Therefore, it is very important to study the relationship between network negative news and stock price fluctuation and provide some reasonable suggestions for the trading activities of stock market participants.
2.2. Related Research Status. With the further development of the securities market and the rapid change of the Internet information age, people gradually pay attention to the important influence of information on the securities market. This has led to scholars' research in this field, which analyzes the impact of media information on securities trading and prices from different levels. Rose [6] is the first to study media information theoretically. Through analysis, he thinks that information can cause stock price fluctuations, but it is difficult for investors to obtain abnormal returns. Niederhoffer [7] in the process of studying the impact of news on the stock market analyzed the news headlines in the New York Times and classified the reported important news into several types according to the different headlines and published contents, evaluated the impact of news headlines on the stock market, and then, studied which major news will have an impact on the stock market. The results show that, on the first day of important news report, the stock market is most affected.

Klibanoff [8] also studied the news headlines of the New York Times, analyzed whether the news would have an impact on the national closed-end funds, and analyzed whether there was news or not through the changes in the price earnings and net asset earnings of the funds.

The results show that, on the one hand, the demand of investors will be affected by news; on the other hand, the elasticity of asset value will also be affected by news. Takeda and Yamazaki [9] used the event study to research NHK's reports. From the news-related companies reported in 190 episodes from 2000 to 2005, they screened 69 listed companies as samples of research and classified them according to industry content and ratings. The results show that the reports of the TV station have an impact on the stock prices of listed companies in all industries. Especially when the content of news report involves product quality and marketing, the effect on stock price is more significant. There are also scholars who study rumors, false information, gossip, and other aspects. Although there are many untrue events in this information, they affect investors' emotions and investment decisions to a certain extent, resulting in the fluctuation of securities prices.

Davies and Canes [10] found that rumors can have a serious impact on the stock price through the "gossip" in the Wall Street Journal, resulting in significant abnormal stock price volatility, and "good" news can bring significant positive abnormal return to investors, while "bad" news can bring negative abnormal return to investors. Smith and Syed [11] found that the day when the rumors were announced, it could bring abnormal returns to investors. In the study of Kiymaz [12], it was believed that four days before the media's public rumors, there is a positive effect on the stock price, and after the media's announcement, there will be a negative effect, but on the whole, this effect is not significant, the effect is not obvious, and only few rumors will have an impact on the stock price. To some extent, this kind of research also verifies the mainstream hypothesis that the stock market has been in a strong and effective state in the 1970s, but some scholars still disagree with this conclusion. In the study of Chan and Wesley [13], by analyzing the abnormal returns 
when there is news or no news, the relationship between the public listed companies' relevant news and their stock returns was verified, and it was found that negative news can have a strong impact on the stock price of the company.

From the behavioral finance theory, we can know that investor sentiment can deeply influence the investment decision making to a great extent. As we all know, investor sentiment is also one of the important factors that affect the fluctuation of securities price in the securities market. If the investor is optimistic about the securities market, the stock price may rise; otherwise, it may fall. Baker and Stein [14] defined investor sentiment in his research: investor sentiment refers to a belief about future cash flow and stock risk that cannot be analyzed and explained with basic information. There are many factors that affect investor sentiment, and negative news is also one of the important factors that affect investor sentiment. Seasholes and $\mathrm{Wu}$ [15] found that stocks with negative information do tend to increase trading volume in the near future. Most investors are highly dependent on the information reported by financial media. Tetlock [16] takes the Wall Street Journal as the research content and analyzes the sentiment of media information from the emotional level. The empirical results show that the higher the pessimism of media information, the greater the possibility of stock market price decline. At the same time, there is a high correlation between the degrees of high and low pessimism and the trading volume of the stock market.

Tetlock and Saar-tsechansky [17] also used Harvard IV to quantify media information into negative information and positive information and found that if a company's news was reported, its stock price would react immediately. Also, by quantifying the company's news, using negative news indicators to predict the company's quarterly earnings, daily earnings, and so on, the results show that the negative information will lead to the decrease of company income and stock income. Some scholars use other research methods.

Catania and Proietti [18] proposed a measurement model that considers the possibly time-varying interaction of realized volatility and asset returns according to a bivariate model to capture its major characteristics: (i) the long-term memory of the volatility process, (ii) the heavytailedness of the distribution of returns, and (iii) the negative dependence on volatility and daily market returns. They assessed the relevance of the effects of "the volatility of volatility" and time-varying "leverage" to the out-of-sample forecasting performance of the model and evaluated the density of forecasts of market volatility. Otaify [19] aimed at examining the volatility properties of equity portfolios sorted according to three firm characteristics: size, value, and financial leverage. The findings indicate that the characteristics-sorted portfolios (CSPs) have different degrees of both volatility clustering and persistence. Moreover, they document the presence of the asymmetric effect, reflecting that bad news has a larger impact on the volatility of the CSPs than the good news of the same magnitude.

In the research field in China, there is little research on the relationship between media news and stock market. In the existing literature, most scholars focus on media information, including positive information, negative information, real information, and false information. Few scholars classify them, so they cannot know more clearly which kind of information affects the stock price. Negative news is one of the important reasons that affect the fluctuation of stock price. Deng [20] studied the stock price changes of food and medicine listed companies in China's A-share market caused by negative public opinion. Based on 261 listed companies in the food and medicine sector, an empirical study on public opinion events of 41 listed companies involved in food and medicine industry was conducted. The results showed that, on the day of public opinion event, the sample has significant negative abnormal returns, and the performance of stock price from the reputation and response attitude of listed companies is analyzed. In the food and drug industry, when the reputable companies are impacted by a public opinion event, the fluctuation range of stock price is smaller than that of the companies with poor reputation.

Liu et al. [21], through the empirical study of event study, found that, with the day when the hearsay was released as $t=0$, investors can obtain positive abnormal return in the time window $(-2,3)$, but in the long run, hearsay news cannot bring any excess return to investors. Zhu [22] used the event analysis method to study 77 public opinion events. Through calculating the daily excess return rate in the event window, he concluded that, on the day of the public opinion event and two days after the event, the impact of the public opinion event on the stock price of listed companies was more obvious. Shi and Xu [23] listed a share in Shanghai and Shenzhen stock markets 119, and the results show that the negative public opinion events have a strong impact on the stock price of listed companies, which is mainly reflected in the sharp decline of the stock price and the negative abnormal rate of return. In addition, this study also studies whether the response attitude of listed companies has an impact on the stock price volatility Through the analysis of the relationship between the three response attitudes of listed companies (interim report, earnings management, and omission) and stock price, it is found that the adoption of interim report can help to resolve various understanding deviations of the public, but the impact on reputation cannot be eliminated in a short period of time; also, the omission response also cannot avoid the abovementioned problems; comparatively speaking, earning management activities can inhibit stock price. The price fluctuation plays a positive role.

Xue et al. [24] showed that, in stock market of some Western countries, most of the investors in the company are easily affected by negative media reports, resulting in a large number of selling off of the shares of listed companies in the stock market, which will eventually lead to bankruptcy of the company. Rao et al. [25] used the listed companies in China's A-share market from 2000 to 2007 as the research samples and explored the impact of the investor's attention on stock returns through empirical tests from two perspectives of "excessive attention to weakness" and "limited attention." The results show that the higher the attention of the report, the worse the stock return of the listed company, and finally, the investors' return is affected. 
In a word, through the review of the relevant literature across the world, we can see that most of the domestic and foreign related research is also focused on the impact of sudden positive or negative, real or false information on the stock price of listed companies, and this information is not classified in the selection of impact information. The research results also directly or indirectly show that the information has an impact on the stock price of the companies involved. After the emergence of various kinds of information on the listed companies, investor sentiment will be affected in the short term, investors will make wrong investment decisions, and then, the company's stock price volatility will be affected, also affecting the company's performance. In the long term, negative information will reduce investors' confidence in listed companies. In this case, investors tend to reduce the investment risk, they will avoid the stock of such companies, and then, the stock price will be affected.

From the literature analysis, we can see that any useful conclusions have gathered the careful research of scholars. It is a step-by-step process from the issue to the corresponding theory, sample selection, data collection, and empirical analysis. In many studies, it is found that the combination of qualitative and quantitative methods and the combination of theoretical and empirical methods make the research results more convincing. Only by selecting samples, collecting data, and then, conducting empirical tests can the research be more meaningful and more aptly reflect the principle that "Practice is the sole criterion for testing truth." The research of this paper is also from the perspective of theory and empirical research in combination. In today's network era, the popularity of intelligent terminals provides a more convenient channel for the dissemination of news reports. The function of news will be further strengthened with the development of media, so the influence of news will be further expanded, and it is of great significance to study the influence of network negative news on the current society. According to the content of the report, we can analyze the impact of financial news in the economic field on China's stock market. The publicity and promotion role of financial news and other public media is becoming increasingly important in today's society, and news will have a certain impact on the stock price through evaluation and publicity. In the rational financial market, the impact of an event will be quickly reflected on the stock price, and the impact of the event will be measured by the change of the stock price in the short term. Therefore, the comparative advantage of the event study method lies in its simple and clear logical clues in the research process, that is, whether the occurrence of an event affects the time-series price problem, and the degree of this impact can be measured by the excess return to calculate.

Some achievements have been made in the research and review of network negative news events at related research status. However, the concept, functional types, and characteristics of network negative news events are similar, but they are repetitive and not deep enough. Secondly, it mainly analyzes the network negative news at different levels, with few theoretical and empirical studies. Finally, with more personal point of view analysis, the theoretical analysis perspective is less. The event research method is used in this study to select a specific event according to the research purpose, to study the changes of sample stock returns before and after the event, and then, to explain the impact of specific events on the changes of sample stock prices and returns. It is mainly used to test the price changes before and after the event or the degree of price response to the disclosure of information. The event study method is based on the efficient market hypothesis; that is, the stock price reflects all known public information. Because investors are rational, investors' reaction to new information is also rational. Therefore, the abnormal return can be obtained by excluding the normal return estimated by assuming that an event does not occur in the actual return of the sample stock. The abnormal return can measure the degree of abnormal reaction of stock price to the event or information disclosure.

Few scholars have classified the related research status, so it is impossible to know which kind of network negative news has an impact on stock price. There are great differences between China and foreign research in the number of documents, naming methods, research topics, theoretical perspectives, research paradigms, and methods. In terms of research topics, China and foreign scholars, respectively, pay attention to management response, negative news events on the Internet, and overview research; in terms of theoretical perspective, Chinese scholars mostly apply communication and public opinion theory and crisis management theory and foreign scholars mainly use social movement theory, discourse, and dialogue theory; in terms of research methods, Chinese scholars mainly use speculative methods and foreign scholars mainly use empirical methods. The differences of this study and the limitations of domestic and foreign studies are different.

\section{Methodology}

3.1. Data Source. The data sources of this paper are as follows: the company's negative news is obtained from Hexun, Netease, Sina News, Fenghuang finance, and other websites, respectively; the stock exchange price, market index, financial report, and other relevant data of listed companies are mainly obtained from guotai'an, tonghuashun, and other databases. In this study, the sampling software is programmed in $\mathrm{C}++$ language. First, a string onedimensional data group is used to save the negative news name, then a string two-dimensional array is used to save the website name, an int array is used to save the number of negative news websites, a string three-digit array is used to save the name of listed companies, and an int two-dimensional array is used to save the number of listed companies. It is traversed eight times; in each traversal, negative news websites are extracted with random numbers, listed companies are extracted from negative news websites with random numbers, and then, the extracted content is output. The main industries are pharmaceutical manufacturing, environment, food, securities, automobile, electrical equipment, and chemical equipment. Among 
them, there were 52 listed companies in regulatory inquiry, 36 listed companies in shareholder crisis, 33 listed companies in regulatory punishment, 34 listed companies in business crisis, 25 listed companies with sharp decline in market value, 23 listed companies with declining performance, and 15 listed companies filed for investigation. The path analysis of network negative news on abnormal stock price fluctuation is shown in Figure 1.

3.2. Sample Selection. The selection of relevant samples is as follows.

3.2.1. Selection of Negative News Samples on the Internet. Firstly, the negative network news is obtained from the data sources described above. The sample range is 2019/01/01 to $2019 / 12 / 31$. The characteristics of the company are controlled, but this study is to analyze the samples pointed out by the Securities Regulatory Commission that there is negative public opinion of the company and sort out the listed companies involved in the relevant negative indicators from 2019. Empirically, the negative data information of the news is relatively objective. The screening principles of the negative network news are as follows:

(1) The negative news events about the listed company, or the negative news events that have been proved to be true, which lead to the fluctuation of the stock price of the company concerned

(2) Negative news events with a clear release date

3.2.2. Sample Selection of Listed Companies. The A-share (Shanghai Stock Exchange and Shenzhen Stock Exchange) listed companies involved in the selected negative news events are taken as the primary sample, and then, they are screened again. The principles are as follows:

(1) Excluding the shares of new listed companies because the price performance of new listed companies has unstable factors, and these shares have overreaction after some stimulation, so they are eliminated.

(2) Excluding the stocks suspended due to other major events within the time window set by the event study method.

(3) Excluding financial stocks and ST stocks: in general, there are many unstable factors in financial stocks, and their stock price fluctuations will be very frequent. In addition, the data research is not meaningful, so it should be excluded; while ST stocks are generally stocks that investors are keen on speculation and their stock price data are not representative, they should also be excluded.

(4) Excluding stocks that have other events during the negative news.

(5) In order to ensure the sample quality, the stocks with incomplete trading data within 10 trading days before the occurrence of negative news shall be excluded.
3.2.3. The Sample Ratio Selection of Individual Stock Financial Data. The data mainly include the company's performance (expressed by ROE and EPS), the concentration of shares in circulation (the proportion of the first major shareholder's shares $\mathrm{H} 1$ and the Hirschman index of the proportion of the first five shareholders' shares (HHI5)), institutional investors' shareholding ratio (INV), corporate reputation (REP), and other ratios mainly based on the financial statements of the previous period before the occurrence of negative Internet news. In the part of sample collection, samples were collected according to the negative indicators, regulatory inquiry, shareholder crisis, regulatory punishment, business crisis, sharp decline in market value, performance decline, and more than 30 times in case filing and investigation counted by the Securities Regulatory Commission in 2019.

3.3. Event Study. Fama's [26] event study methodology has been extensively used in finance and accounting research. This method concentrates on measuring abnormal performance of financial assets caused by a special event. Although event study methods are well developed and often used to test financial theories for the US and other well-established stock exchanges, there is some concern regarding efficiency when applied to small stock exchanges dominated by thinly traded stocks (i.e., stocks that do not trade every day). In small stock markets, there are hardly continuous daily price data for many shares. Event study is also widely used in the field of behavioral finance and accounting; because of its clear thinking and clear logic, event study has been used by many scholars and gradually become popular, becoming a classic research tool. The whole process of event study mainly includes the following steps, and the specific operations are as follows:

(1) Event selection

The key to the event study method is to make clear the types of relevant events and information to be studied and to determine the time range of influencing stock price changes. The basic premise of event study is that the market is effective; that is, the current stock reflects all stock market-related stock price information. Therefore, in the process of selecting research events, we should first select the events that occur independently during the observation period, so as to avoid the situation that other events in the observation period lead to the interference of research results and inaccurate research conclusions.

(2) Time window selection

There is no specified mode for the selection of time window range. In the application of event study, we can choose at will which depends on the research situation. Before determining the time window, the event date should be determined first. After the event date is determined, the event window should be determined. The event window can be divided into long-term event window $(-30,30),(-60,60)$, and 


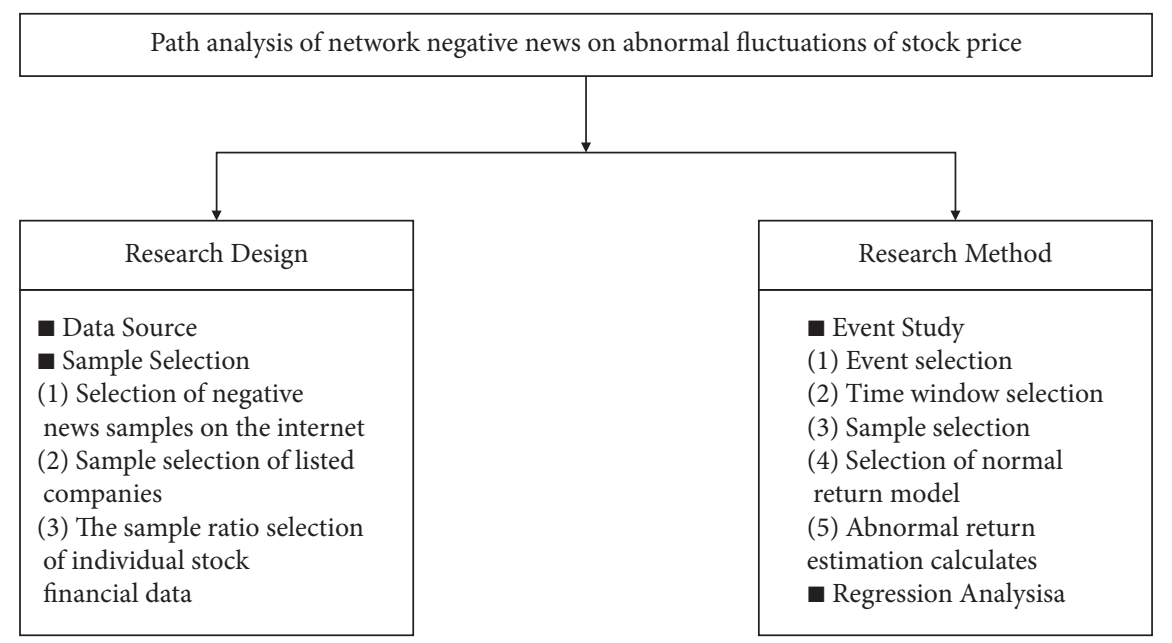

FIGURE 1: Path analysis chart of network negative news on abnormal fluctuation of stock price.

$(-180,180)$ and short-term event window $(-1,1)$, $(-3,3),(-5,5),(-10,10)$, etc. The time window is divided into estimation window, event window, and postevent window.

As for the selection of time window, Ren [27] selected $[-120,20]$ as the time window of the whole event study when studying the impact of environmental events on the stock price. Taking $[-120,-20]$ as the estimation window and $[-20,20]$ as the event window, the study found that the stock price began to react within 2 to 3 days after the event, with a short duration, and the abnormal return rate began to recover to be positive after 3 to 4 days. Liu [21] made an empirical analysis of the impact of hearsay on the stock price by using the event study method, taking the day when the hearsay was released as $t=0$. In the time window $[-2,3]$, hearsay can bring abnormal return rate to investors, but in the long run, hearsay cannot bring any abnormal return rate to investors. After comprehensive consideration, this paper takes the release date of negative news on the Internet as the event day $t=0$ and chooses the first 10 trading days and the last 10 trading days as the time window of this study, namely, $[-10,10]$. If the time window selection is too long, there may be other interference factors, resulting in low accuracy of settlement results; if the time window selection is too short, the data may be limited, and the results will also be affected, so it is necessary to obtain the stock yield and corresponding market index yield data of the first 10 trading days and the next 10 trading days before the negative news release date.

\section{(3) Sample selection}

When selecting samples, it is necessary to select stocks that may be affected by events, some events may only affect one stock, and some events may affect an industry sector. Therefore, when selecting samples, it is necessary to consider the industry restrictions, the availability of data, and the limit standards of samples to improve the quality of research.

(4) Selection of a normal return model

The normal rate of return is the sample expected rate of return in the future event window without any event impact. To estimate the impact of a certain information disclosure on the stock price, first of all, we predict the future income level and establish the expected model. At present, the most commonly used models in the research are as follows:

According to the market adjustment model, the return of all sample stocks is the same as that of the market index corresponding to the same period; that is, the expected rate of return in the event window can be expressed as follows:

$$
E R_{i t}=R_{m t},
$$

where $E R_{i t}$ is the expected yield of the $i$ stock in the $T$ period and $R_{m t}$ is the real yield of a market index in the $T$ period. In China, the Shanghai Composite Index, Shenzhen Composite Index, and A-share composite index are usually used to replace the market index.

The mean adjustment model assumes that the expected rate of return of the sample stock in the event window is a constant, and this constant is equal to the average value of all the rates of return of the sample stock in the past period of time, that is, in the estimation window; the market model is a combination of the mean adjustment model and the market adjustment model, which considers both the historical data and the future data of the stock, and the market model considers that there is a linear relationship between the future yield (normal yield) of a security in the window and the market yield in the same period. Therefore, the model for calculating the normal rate of return is as follows:

$$
E R_{i t}=\alpha_{i}+\beta_{i} R_{m t}+\varepsilon_{i t},
$$


where, dependent variable $E R_{i t}$ refers to the yield of stock I in period $T$, independent variable $R_{m t}$ is the yield of the market index in period $T, \alpha_{i}$ is the intercept of the individual stock regression model, $\beta_{i}$ is the regression coefficient of the individual stock regression model, and $\varepsilon_{i t}$ is the residual term of the regression model, which is assumed to be normal distribution.

However, the three models have their own advantages and disadvantages. When we study daily data and monthly data, the market model will be more effective. However, for the abovementioned situation, the market adjustment model may also obtain better results. Chen and Chen [28] used 951 companies listed in the Shanghai and Shenzhen stock markets from 1990 to 2000 as research samples to test the effectiveness of the abovementioned three models. The results proved the limitations of the market model and the market adjustment model. All have certain advantages in the Chinese stock market, but it is easy to reject the original hypothesis when using the market model to study the Chinese stock market. It is easy to fail to achieve the expected effect when using the market model to study the situation of small stock price response, and the application process of the market model depends on the selection of estimation window. The stability of data in the estimation window seriously affects the goodness of fit of OLS regression. Only when the goodness of fit is high, it has the ability to interpret. In the research of Chen and Jiang [29], it was believed that there are systematic risks that cannot be ignored in China's securities market, so using the mean adjustment model to study China's securities market also fails to achieve the desired results. According to the needs of the research purpose, this article selects a market adjustment model to study the impact of negative online news on the stock prices of listed companies.

(5) The abnormal return estimation calculates the daily data of the agnominal return rate in the event window:

$$
\mathrm{AR}_{i t}=R_{i t}-R_{m t} .
$$

Here, $\mathrm{AR}_{i t}$ is the abnormal yield of the $i$ th stock in the $T$ period, $R_{i t}$ is the actual yield of the $i$ th stock in period $T$, and $R_{m t}$ is the real yield of market index (Shanghai Composite Index and Shenzhen composite index are used in this paper) in the $T$ period.

Calculation of the Average Agnominal Return (AAR): the purpose is to investigate the abnormal return of the sample stock. The Average Agnominal Return of the sample data is the weighted average of the abnormal return of all the sample stocks, namely,

$$
\operatorname{AAR}_{t}=\frac{1}{n} \sum_{i=1}^{n} \mathrm{AR}_{i t} .
$$

Among them, $\mathrm{AAR}_{t}$ is the Average Agnominal Return of all samples in time $t$ in the event window.
The purpose of calculating CAR (Cumulative Average Return) is to investigate the cumulative effect on time series. After calculating the Average Agnominal Return, we calculate the average $\mathrm{Cu}$ mulative Average Return as follows:

$$
\operatorname{CAR}_{\left(t_{1}, t_{2}\right)}=\sum_{t_{1}}^{t_{2}} \operatorname{AR}_{i t} \text {. }
$$

In the abovementioned formula, $\mathrm{CAR}_{\left(t_{1}, t_{2}\right)}$ indicates that the stock is in $\left(t_{1}, t_{2}\right)$ Cumulative Average Return during the period.

(6) The significance test of abnormal return shows that the cumulative average return can be divided into positive and negative.

If the cumulative average return is positive, it means that the investigated event has a positive impact on the stock price; if the cumulative average return is negative, it means that the investigation incident had a negative impact on stock prices. But, this is not sufficient. Only when the positive or negative impact reaches a certain level of significance can we make a conclusion, so we need to test the significance of cumulative average return. There are two methods to test abnormal return or cumulative abnormal return; one is the parametric test, and the other is the nonparametric test. The parametric test usually refers to the mean $t$-test, which tests the difference between the mean value of abnormal return and 0 . If the $p$ value is less than 0.05 , the abnormal return is not equal to 0 , which means the significance test is passed; that is to say, the event has an impact on the stock market. If it fails to pass the significance test, i.e., $p$ value is greater than 0.05 , then there is no significant difference between the mean value of abnormal return and 0 , and the event has no impact on the stock market. The Wilcoxon signed rank sum test is often used in the nonparametric test, which is suitable for samples with unknown distribution form or distribution type, but its test efficiency is lower than that of the parametric test. Therefore, when we test the significance of abnormal returns, we should first consider the parameter test.

\subsection{Regression Analysis}

3.4.1. Research Hypothesis. The results obtained by using the event study method can only prove whether the Internet negative news has an impact on the stock price fluctuation of the involved company, but how will it affect it? Therefore, this paper uses the regression analysis method, from the perspective of companies involved, to investigate which factors will affect the stock price volatility.

There are two important factors in stock market, which are listed companies and investors. The performance of companies is one of the most concerned factors. When negative news events occur in listed companies, it is easy for investors to be affected in varying degrees and cause them to 
have psychological effects of anxiety, thus resulting in pessimistic psychology and affecting investment decisions. In this situation, investors will have a pessimistic mood about the future earnings of enterprises, and the general investors tend to reduce the risk. At this time, if the company's performance is still good, it can bring emotional comfort to investors, ease the panic psychology so that investors will not be able to sell the stock instantaneously, and reduce the fluctuation of stock price. Zhang and Shen [30] found that negative news does not have a significant impact on stock returns under the optimistic state of the market; the market with widespread pessimism loses its value discovery function, and the abnormal rate of return continues to decline; the negative impact of stabilizing sentiment on the market lasted for 12 days, followed by signs of value recovery of yield recovery. Therefore, Hypothesis 1 is proposed.

Hypothesis 1. When the listed companies burst out the network negative news, the performance of the companies involved is significantly related to the stock price movements.

In China's securities market, shareholders can be roughly divided into three categories: major shareholders of tradable shares, institutional investors, and retail investors. When the listed companies burst into negative news, the behavior of shareholders easily causes the fluctuation of stock price, and the behavior of shareholders is based on their psychological expectation and a series of complex external environments to make investment decisions, and these decisions are generally produced in a short period of time. From the perspective of shareholding ratio, what can have a significant impact on the stock price volatility should be known. Therefore, to some extent, the ownership structure of tradable shares can also play a certain role in stabilizing the trend of stock price. If the shareholding ratio of major shareholders of a certain stock is highly concentrated, the control over the trend of stock price is more effective; on the contrary, if the ownership structure of a stock is more dispersed, the large shareholder will control the stock price trend and lower the control effect of price movements. Therefore, Hypothesis 2 is proposed.

Hypothesis 2. When the listed companies burst out the network negative news, the concentration of shares in circulation of the involved companies is significantly related to the stock price changes.

For a company, corporate reputation is like an intangible asset, more like a commercial reservoir, which can effectively alleviate the adverse impact of certain "events" on the company to a certain extent. Fombrun [31] believes that the company reputation is positively correlated with the company's stock returns. On the contrary, Debondt [32] thinks that there is no obvious relationship between the company's reputation and its stock price, and the company with good reputation does not necessarily have a high return. Therefore, different scholars hold different opinions on whether the company's reputation will affect the stock price. When a listed company breaks out negative news, does the reputation of the company affect the fluctuation of stock price? Therefore, Hypothesis 3 is proposed.

Hypothesis 3. The reputation of the companies involved is significantly related to the change of stock price when the listed companies have sudden negative network news.

Qi et al. [33] selected A-share listed companies listed on the Shanghai Stock Exchange from 2001 to 2004 as samples to empirically test the relationship between the shareholding ratio of institutional investors and the fluctuation of stock prices. The research results show that the shareholding ratio of institutional investors has an obvious negative effect on the abnormal volatility of stock price. He et al. [34] also studied the viewpoint of whether institutional investors can stabilize the stock market. The empirical test results show that the impact of institutional investors' shareholding ratio on the stock market does not reach a consistent conclusion, which shows that institutional investors sometimes have positive effects on the stock market and sometimes have negative effects. Although the abovementioned scholars have not reached a unified view on whether institutional investors have an impact on stock prices, we can see that institutional investors do have more or less impact on stock prices, whether positive or negative. Therefore, Hypothesis 4 is proposed.

Hypothesis 4. When the listed companies burst out the network negative news, the proportion of institutional investors in the companies involved has a significant effect on the stock price changes.

3.4.2. Variable Selection and Definition. As the content of this study is the impact of Internet negative news on stock prices, how to define its impact? Therefore, this paper uses the market adjustment model of event study to quantify the impact of network negative news on stock price, calculates the cumulative average return (CAR) within the time window of network negative news influence, and takes the cumulative average return (CAR) within the time window as the dependent variable of the regression model. In the research of Tao and Liu [35], they also believed that, in the event of an emergency, there will be more or less impact on China's stock market, but the shareholding ratio of institutional investors and the top five major shareholders of tradable shares can effectively increase or reduce the fluctuation of stock price to a certain extent. Therefore, this paper establishes a regression model based on the independent variables of the listed company's performance (expressed by ROE and EPS), the concentration of shares in circulation (H1 and hhi5 of the largest shareholder), INV, and REP. Asthana et al. [36] found that, with the exception of Deloitte \& Touche, clients of the other Big 5 auditors experienced share price declines during one or both windows following negative disclosures about Andersen. This paper examines whether the relevant variables of listed companies have an impact on the abnormal volatility of stock prices and explains the regression results. The selection and definition of variables are shown in Table 1. 
TABLe 1: Selection and definition of variables.

\begin{tabular}{|c|c|c|c|c|}
\hline & $\begin{array}{l}\text { Variable } \\
\text { code }\end{array}$ & Definition & Quantitative method & Unit \\
\hline \multirow[t]{3}{*}{$\begin{array}{l}\text { Dependent } \\
\text { variable }\end{array}$} & CAR & Cumulative average return & $\sum_{t_{1}}^{t_{2}} \mathrm{AR}_{i t}$ & $\%$ \\
\hline & $\begin{array}{l}\text { EPS } \\
\text { ROE }\end{array}$ & $\begin{array}{l}\text { Earnings per share } \\
\text { Return on equity }\end{array}$ & $\begin{array}{l}\text { Net profit/general capital } \\
\text { Net profit/net assets }\end{array}$ & $\begin{array}{c}\text { Yuan/share } \\
\%\end{array}$ \\
\hline & $\mathrm{H} 1$ & $\begin{array}{l}\text { Shareholding ratio of the largest } \\
\text { shareholder }\end{array}$ & Stock ownership/total shares outstanding & $\%$ \\
\hline \multirow{3}{*}{$\begin{array}{l}\text { Independent } \\
\text { variable }\end{array}$} & HHI5 & Herfindahl-Hirschman index & Sum of squares & $\%$ \\
\hline & REP & Corporate reputation & $\begin{array}{c}\text { The number of company violations is taken from } \\
\text { the natural logarithm }\end{array}$ & Times \\
\hline & INV & $\begin{array}{c}\text { Institutional investor shareholding } \\
\text { ratio }\end{array}$ & Institutional investor holdings/total share capital & $\%$ \\
\hline
\end{tabular}

3.4.3. Model Establishment. According to the hypothesis of this paper, the Cumulative Average Return (CAR) is used as the explanatory variable of the regression model, and EPS, ROE, H1, HHI5, and INV are used as explanatory variables. The following models were established:

$$
\begin{aligned}
\mathrm{CAR}_{i}= & \alpha_{0}+\beta_{1} \mathrm{EPS}_{i}+\beta_{2} \mathrm{ROE}_{i}+\beta_{3} \mathrm{H}_{i}+\beta_{4} \mathrm{HHI}_{i} \\
& +\beta_{5} \mathrm{LnREP}_{i}+\beta_{6} \mathrm{INV}_{i}+\varepsilon_{i},
\end{aligned}
$$

where $\varepsilon_{i}$ is expressed as a random disturbance term and $i$ is the number of samples of listed companies.

\section{Empirical Results and Analysis}

\subsection{Market Effect Analysis of Negative News of Listed Companies}

\subsubsection{Data Processing}

(1) Data Extraction in Time Window. Taking the release date of negative news of listed companies as the center, the daily return rate of individual stocks, the daily trading volume of single stock, and the corresponding daily return rate of market index of 10 trading days before and after the event date are extracted from the downloaded yield sample database from 2018 to 2019. The sample stocks selected in this paper are listed in Shenzhen Stock Exchange and Shanghai Stock Exchange, so we choose the market index corresponding to the daily yield data of Shenzhen Stock Index and Shanghai Composite Index. In addition, considering the data requirements of regression analysis later in this paper, only one data is retained if there are more than two events in the sample. Through the abovementioned screening, 218 valid samples were obtained.

(2) Calculation of Abnormal Return. According to the research model selected in this paper, the abnormal return, average Cumulative Average Return, and Cumulative Average Return in the time window are calculated. The abovementioned operations are completed in the database with SQL statements.

\subsubsection{Descriptive Analysis}

(1) Abnormal Rate of Return (AR) Analysis. This paper selects the daily returns of listed companies on the day of negative news, that is, the ten trading days before and after the $t$ day. The time window of the event study is $[T-10, T+10]$; we calculate the abnormal returns of individual stocks within each trading day and then conduct descriptive statistical analysis on the daily abnormal returns of all sample stocks within the time window. Table 2 shows the results of descriptive statistical analysis on the daily abnormal returns of all sample stocks within the time window.

Table 2 shows the maximum value, minimum value, mean value, and standard deviation of abnormal return rate of listed companies on the date of occurrence of negative news events and 10 days before $(T-10)$ and 10 days after $(T+10)$. On the day of negative news $(T)$, among 218 listed companies, 87 listed companies have negative abnormal return $s$, and 131 companies have abnormal returns greater than 0 . This shows that the outbreak of network negative news on the stock prices of listed companies is not only necessarily a negative effect but also has a positive effect. According to the standard deviation, the fluctuation of the first day $(T+1)$ and the second day $(T+2)$ after the event is obvious, which indicates that the risk on the first day $(T+1)$ and the second day $(T+2)$ after the event is more significant than that in other times.

From the results shown in Table 2, it can be seen that the average abnormal yield of the stock showed a downward trend from the day before the negative news release day $(t-1)$ and did not rise until the third day $(T+3)$ after the negative news release day, which seems to indicate that the stock market has already reacted to the negative news events of listed companies The municipal company responded to and dealt with the negative news events. But, do the negative news events of listed companies have a significant impact on the stock price? It may not be meaningful to judge the reaction degree of stock price only by the analysis of abnormal return. Therefore, the following is an analysis of Average Agnominal Return (AAR) and Cumulative Average Return (CAR).

(2) Average Agnominal Return and Cumulative Average Return (AAR and CAR) Analysis. Average Agnominal Return (AAR) is the average value of all sample stocks in each trading day before and after the occurrence of negative news. Descriptive statistical analysis is conducted on the average abnormal return and cumulative abnormal return within the time window, and the overall change of all sample 
TABle 2: Descriptive analysis of abnormal returns.

\begin{tabular}{|c|c|c|c|c|c|}
\hline Time (day) & Number of samples & Maximum & Minimum & Average & Standard deviation \\
\hline$T-10$ & 218 & 0.1433 & -0.0771 & 0.0030 & 0.0259 \\
\hline$T-9$ & 218 & 0.1082 & -0.0989 & 0.0004 & 0.0285 \\
\hline$T-8$ & 218 & 0.1566 & -0.1155 & 0.0011 & 0.0262 \\
\hline$T-7$ & 218 & 0.1339 & -0.0758 & 0.0037 & 0.0278 \\
\hline$T-6$ & 218 & 0.1031 & -0.1157 & 0.0013 & 0.0243 \\
\hline$T-5$ & 218 & 0.1102 & -0.1155 & 0.0005 & 0.0280 \\
\hline$T-4$ & 218 & 0.1235 & -0.1155 & -0.0002 & 0.0285 \\
\hline$T-3$ & 218 & 0.0968 & -0.1026 & 0.0010 & 0.0291 \\
\hline$T-2$ & 218 & 0.1726 & -0.1051 & 0.0018 & 0.0295 \\
\hline$T-1$ & 218 & 0.1179 & -0.1016 & 0.0003 & 0.0305 \\
\hline$T$ & 218 & 0.0746 & -0.1035 & -0.0025 & 0.0308 \\
\hline$T+1$ & 218 & 0.0953 & -0.0925 & -0.0051 & 0.0304 \\
\hline$T+2$ & 218 & 0.1000 & -0.0782 & -0.0044 & 0.0307 \\
\hline$T+3$ & 218 & 0.1051 & -0.0685 & -0.0017 & 0.0293 \\
\hline$T+4$ & 218 & 0.1080 & -0.0912 & 0.0036 & 0.0307 \\
\hline$T+5$ & 218 & 0.0899 & -0.1148 & -0.0009 & 0.0272 \\
\hline$T+6$ & 218 & 0.1179 & -0.0800 & 0.0030 & 0.0277 \\
\hline$T+7$ & 218 & 0.1151 & -0.1150 & 0.0036 & 0.0271 \\
\hline$T+8$ & 218 & 0.0999 & -0.1264 & -0.0009 & 0.0260 \\
\hline$T+9$ & 218 & 0.1001 & -0.0942 & -0.0034 & 0.0261 \\
\hline$T+10$ & 218 & 0.0963 & -0.0760 & -0.0003 & 0.0238 \\
\hline
\end{tabular}

stocks in the time window is observed. The statistical analysis results are shown in Table 3.

It can be seen from Table 3 and Figure 2 that, on the day (T) of negative news of listed companies, the cumulative average return changed from 0.0655 on the trading day before the event date to -0.5413 , and on the day after the event $(T+2)$, the negative cumulative abnormal return dropped sharply to -1.1075 , with a decrease rate of $104.6 \%$. Within the 21 trading days of the time window, the $\mathrm{cu}$ mulative average return of 9 trading days is negative, mainly distributed in the negative news day and the trading day after the negative news event. Therefore, it can be explained that when the negative news event occurs in the listed company, it has a certain effect on the fluctuation of its stock price, and we can also see that the negative news events have a negative impact on the stock price.

4.1.3. Significance Test of Abnormal Return Rate. The abovementioned results almost show that, from $T-2$ to $t+4$ after the outbreak of negative news of listed companies, the volatility of stock price is large, and there are obvious negative abnormal returns. Therefore, the abnormal return data of two trading days before and four trading days after the outbreak of negative news events are selected, and the $t$ test is conducted to obtain the time window [T-2]. The significant coefficient values and $T$ values of each stock trading day in $T+4]$ are seven groups, as shown in Table 4 .

It can be seen from Table 4 that the significant coefficient value of $T+1$ is 0.015 , which is significant at the 0.05 level, and the significant coefficient value of $T+2$ is 0.018 , indicating that it is significant at the 0.05 level. On the day of the outbreak of negative news events, the abnormal returns are not significant, which indicates that there is a lag period for investors' acceptance and understanding of such emergencies, which does not show immediately. Two days after
TABLE 3: Cumulative abnormal return.

\begin{tabular}{lcc}
\hline Time (day) & Average & Cumulative abnormal return (CAR) \\
\hline$T-10$ & 0.0030 & 0.6510 \\
$T-9$ & 0.0004 & 0.0869 \\
$T-8$ & 0.0011 & 0.2446 \\
$T-7$ & 0.0037 & 0.8022 \\
$T-6$ & 0.0013 & 0.2877 \\
$T-5$ & 0.0005 & 0.1007 \\
$T-4$ & -0.0002 & -0.0523 \\
$T-3$ & 0.0010 & 0.2182 \\
$T-2$ & 0.0018 & 0.3833 \\
$T-1$ & 0.0003 & 0.0655 \\
$T$ & -0.0025 & -0.5413 \\
$T+1$ & -0.0051 & -1.1075 \\
$T+2$ & -0.0044 & -0.9572 \\
$T+3$ & -0.0017 & -0.3599 \\
$T+4$ & 0.0036 & 0.7827 \\
$T+5$ & -0.0009 & -0.2017 \\
$T+6$ & 0.0030 & 0.4558 \\
$T+7$ & 0.0036 & 0.7765 \\
$T+8$ & -0.0009 & -0.1967 \\
$T+9$ & -0.0034 & -0.7320 \\
$T+10$ & -0.0003 & -0.0723 \\
\hline
\end{tabular}

the outbreak of the event, there is a significant abnormal return, which shows that the outbreak of negative news events makes the daily activity of the stock market significantly increased, and finally, there is an obvious abnormal return. However, after the third day of the event, the abnormal return is not obvious, which means it is very likely that the impact of the stock market on negative news events has gradually weakened, and there is no obvious correlation between them. It shows that although negative news will cause abnormal stock price fluctuation in a short period of time, after the occurrence of negative news events, general companies will try their best to rescue or reduce the harm 


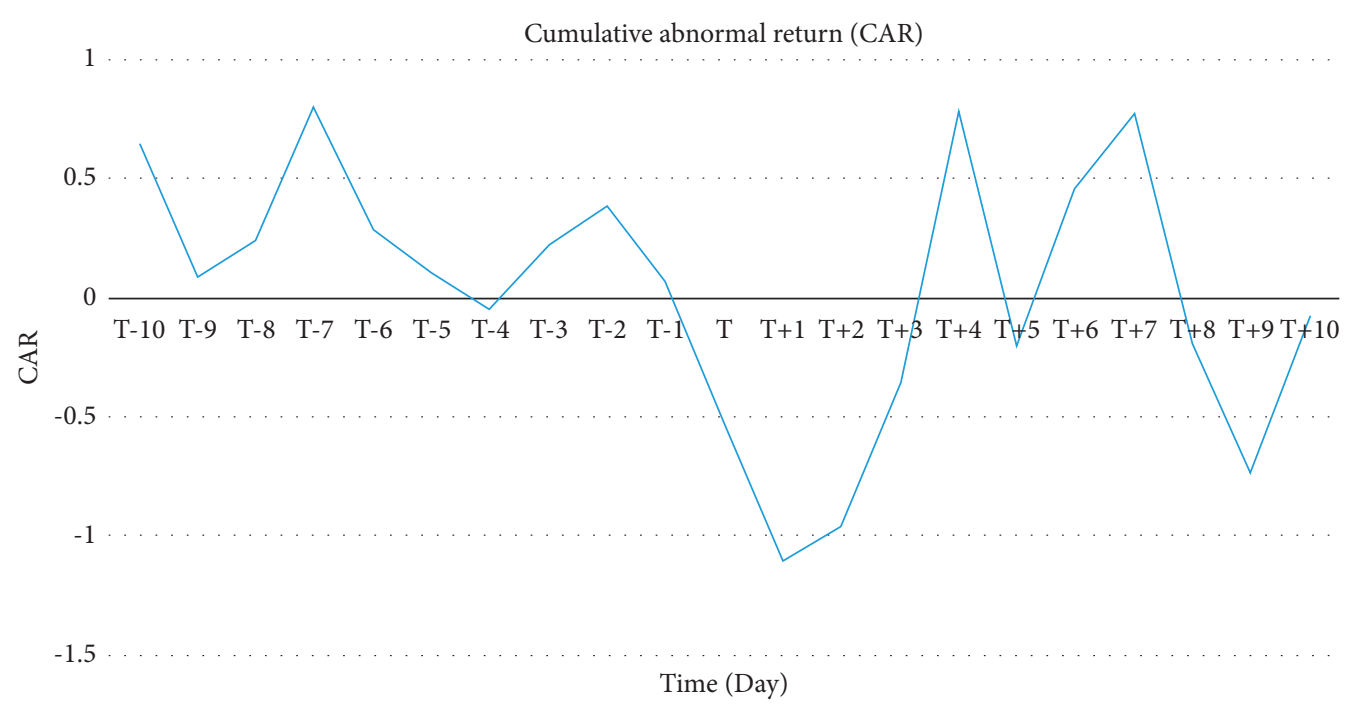

FIGURE 2: Fluctuation chart of cumulative abnormal return.

TABLE 4: $T$ test of abnormal return rate.

\begin{tabular}{lccc}
\hline Time (day) & Means (AR) & Significance & $T$ value \\
\hline$T-2$ & 0.0018 & 0.382 & 0.876 \\
$T-1$ & 0.0003 & 0.880 & 0.151 \\
$T$ & -0.0025 & 0.184 & -1.333 \\
$T+1$ & -0.0051 & 0.015 & $-2.441^{* *}$ \\
$T+2$ & -0.0044 & 0.018 & $-2.390^{* *}$ \\
$T+3$ & -0.0017 & 0.350 & -0.936 \\
$T+4$ & 0.0036 & 0.062 & $1.878^{*}$ \\
\hline
\end{tabular}

${ }^{* *},{ }^{*}$ indicate significance at 0.05 and 0.1 levels, respectively.

caused by negative news events so that their stock prices return to stable.

\subsection{Analysis of Influencing Factors of Stock Price Fluctuation of} Listed Companies. Through the use of event study to study the unexpected network negative news events of listed companies, the research results show that the negative news of listed companies has a significant impact on the stock price fluctuation, but how does it affect it? The stocks issued by listed companies and the investors who buy stocks constitute the most important two factors in the stock market, namely, investors and listed enterprises. Investors will have different investment bases when buying the stocks of listed companies, but most rational investors will pay attention to all aspects of information given by listed companies and then make investment decisions based on important information. What information of the listed companies will affect the investors' investment decisions and, thus, affect the abnormal fluctuation of the stock price? Therefore, on the basis of using event study to get the research results, this paper conducts regression analysis on the relevant information of listed companies again, trying to test which factors affect investment decisions and stock price fluctuations. The regression model established in this paper is obtained by event study. Cumulative Average Return (CAR) was selected as the dependent variable, and the return on equity (ROE), earnings per share (EPS), the largest shareholder's shareholding ratio $(\mathrm{H} 1)$, the shareholding ratio of the top five circulating shareholders (represented by HHI5), institutional investors' shareholding ratio (INV), and corporate reputation (REP) were selected as independent variables for regression analysis, Table 5 .

The adjusted $R$ square is used to judge the goodness of fit of the regression model. The closer to 1 , the better the fitting effect is. Zhao [37] showed that if the $R$ square of a model is very small, it does not necessarily mean that there is no relationship between the data. The larger the $R$ square, the better the fitting because $R$ square is only the proportion of the sum of regression squares to the total sum of squares. However, it is generally accepted that the adjusted $R$ square of the economic model is greater than 0.2 , so the fitting result of the model can be considered acceptable. From Table 5, we can see that the adjustment of $R$ squared is 0.291 , which indicates that the fitting effect of the model is better. The $F$ value was 15.832 , which was significant at the 0.01 level, indicating that the model fitting was established.

According to the overall research results in Table 5, the return on equity (ROE), earnings per share (EPS), and the shareholding ratio of institutional investors (INV) are significant at the level of 0.05 , the shareholding ratio of the top five circulating shareholders (HHI5) is significant at the level of 0.01 , and the shareholding ratio of the largest shareholder of circulating shares (H1) is significant at the level of 0.1 . However, rep is not significant. Generally, ROE and EPS can represent the company's performance. When a listed company has a sudden negative news event, it easily affects the investor's sentiment and makes the investor fall into anxiety in the short term, which will produce a negative effect and affect the investment decision making. In this situation, investors will be pessimistic about the company's future earnings to reduce risk. At this time, if the company's performance is still good, it can bring emotional comfort to investors, ease the panic psychology so that investors will not be able to sell the stock instantaneously, and reduce the fluctuation of stock price. From Table 5, it can be seen that, 
TABLE 5: Regression analysis of cumulative abnormal return.

\begin{tabular}{lccc}
\hline & Regression coefficient & $T$ value & Significance \\
\hline Constant & 0.0348 & 1.2001 & 0.2315 \\
EPS & -0.0387 & $-2.1565^{* *}$ & 0.0322 \\
ROE & -0.1506 & $-2.0002^{* *}$ & 0.0468 \\
H1 & -0.2105 & $-1.6737^{*}$ & 0.0957 \\
HHI5 & 0.4766 & $3.4833^{* * *}$ & 0.0006 \\
LnREP & -0.0109 & -1.3683 & 0.1727 \\
INV & -0.0867 & $-2.0190^{* *}$ & 0.0447 \\
$F$ & & $15.832^{* * *}$ & \\
Adj- $R^{2}$ & & 0.291 & \\
VIF & & 1.356 & \\
\hline
\end{tabular}

${ }^{* * *},{ }^{* *}$, and ${ }^{*}$ indicate significance at $0.01,0.05$, and 0.1 levels.

in other words, when the ROE and EPS of a listed company are higher, the volatility of stock price will be smaller after the occurrence of negative news, which indicates that the listed company with good performance can give investors a signal of safe investment and make them more willing and confident to continue to hold stocks. Therefore, compared with the listed companies with poor performance, the stock price fluctuation of good performance listed companies is relatively small when affected by negative news.

It can be seen from the regression analysis results in Table 5 that the shareholding ratio of the largest shareholder (H1) and the shareholding ratio of the top five shareholders (HHI5) are significant, and the significance of the shareholding ratio of the largest shareholder of the circulating shares is lower than that of the top five shareholders. When the negative news of listed companies breaks out, the behavior of shareholders easily causes the fluctuation of stock price. The behavior of shareholders is based on their psychological expectation and a series of complex external environments to make investment decisions, and these decisions are generally produced in a short period of time, and it should be the major shareholders and institutional investors who can have a significant impact on the stock price fluctuation. Therefore, to some extent, the ownership structure of tradable shares can also play a certain role in stabilizing the stock price trend. If the shareholding ratio of the major shareholders of a certain stock is highly concentrated, the control over the stock price trend is more effective; on the contrary, if the ownership structure of the circulating shares of a certain stock is highly concentrated, the control of the stock price trend is more effective. The more dispersed the ownership structure of the stock, the lower the control effect of large shareholders on the stock price trend.

Institutional investors generally have higher investment professional knowledge and strong analytical ability. Therefore, when encountering unexpected negative news of listed companies, they are more likely to use effective information to analyze and make better investment decisions, instead of following blindly and other irrational behaviors. According to the results of regression analysis in Table 5, there is a negative correlation between the shareholding ratio of institutional investors (INV) and cumulative abnormal returns; that is, the higher the shareholding ratio of institutional investors is, the more stable the stock price fluctuation is and the smaller the fluctuation range of stock price is, and it can stabilize the stock price fluctuation to a certain extent.

According to the regression analysis results in Table 5, the significance of REP of listed companies is not obvious. This may also be due to the variable of corporate reputation. From the perspective of investors, it is not easy for investors to quantify corporate reputation. Therefore, in investment decision-making activities, the company's reputation is not taken into account too much, and what are the listed companies that often have all kinds of major events can be concerned by investors. In the regression analysis of this paper, the number of violations of listed companies is used to quantify the reputation of companies. When negative news occurs in listed companies, in the case of sudden and short term, the number of violations of listed companies is generally not easy to be concerned by investors. Therefore, this move may lack persuasion.

First of all, we use event study to study the negative news to determine whether the occurrence of negative news events has a significant impact on the stock price of listed companies. The results show that negative news can have a significant impact on the abnormal volatility of stock prices of listed companies. Secondly, the regression analysis method is used to analyze the influencing factors of stock price. The results show that the company performance, the proportion of the first major shareholder of tradable shares, the proportion of the top five major shareholders of circulating shares, and the proportion of institutional investors have a significant correlation with cumulative abnormal return, while the reputation of listed companies is not significant. From the results of regression analysis and combined with the research hypothesis, Hypothesis 1, Hypothesis 2, and Hypothesis 4 have been verified, while Hypothesis 3 has not been verified.

\section{Conclusions and Suggestions}

5.1. Research Conclusion. This paper defines the occurrence of network negative news of listed companies and selects A-share listed companies listed on Shanghai Stock Exchange and Shenzhen Stock Exchange as research samples. By using the event study, selecting the time window of event study, the corresponding calculation and significance test are carried out. The research results are obtained and then combined with regression analysis for further research, and finally, the following conclusions are drawn:

(1) Internet negative news can affect the stock price fluctuation of listed companies. From the research results of the event study method, the stock price volatility is more serious after the occurrence of negative news in listed companies, which indicates that the occurrence of negative news has a certain impact on investors and, therefore, proves that the stock market is highly sensitive to sudden negative news events. Negative news has positive and negative effects on stock price. 
(2) Internet negative news makes the stock price of listed companies more active in the short term. The results of the research on the negative news events of listed companies through the event study show the negative news events of listed companies from $T-1$ before the occurrence of negative news to the four trading days after the occurrence of negative news $T+4$; in this period of time, the stock price volatility is the most active state, and the fluctuation range is large, which indicates that the negative news has a relatively serious impact on the listed companies in the short term, which makes investors panic, and finally causes the stock price to become more active in the short term.

(3) The performance of listed companies has a significant impact on stock price volatility. From the results of the event study and regression analysis, we also know that when the negative news occurs in the listed companies, the higher the return on shareholders' equity and earnings per share is, the less the volatility of the stock price is. This shows that the better performance of listed companies, because of their better profitability, can make investors generate more income. Therefore, when the listed companies with good performance have negative news events, investors may consider their profitability and investment effects more, and they are willing to believe that negative news events are only short-term effects and will not cause greater losses. Investors have high self-confidence in the listed companies with good performance, so investors are more willing to continue to hold stocks after weighing the pros and cons. The stock price fluctuation of listed companies with high performance is small.

(4) The concentration of shares in circulation and stock price fluctuation has an impact on stock price volatility. In general, the major shareholders of tradable shares in listed companies can effectively control the price trend of stocks, which plays an important role in the stock market. In the research results of this paper, the top five major shareholders' shareholding ratio has a greater impact than the first largest shareholder, and the direction of influence is also opposite; that is, the top five major shareholders can reduce the volatility of the listed company's share price, while the first largest shareholder can increase the fluctuation range of the listed company's stock price; otherwise, it shows that, in the case of negative news, each major shareholder's share price volatility is significantly higher than that of the first largest shareholder. Dong's investment decisions are not all consistent, or even slightly offset the effect. But, generally speaking, the concentration of shares in circulation of listed companies has a significant impact on stock price volatility.

(5) Institutional investors have a stable effect on the stock price fluctuation of listed companies. The results of regression analysis show that institutional investors and cumulative abnormal returns are negatively correlated. That is to say, when the listed companies have negative news, institutional investors can effectively restrain the volatility of stock price. The higher the proportion of institutional investors, the smaller the fluctuation range of stock price, which indicates that institutional investors can list stably to a certain extent the share price of the company and reduce its fluctuation range so that its abnormal return is also reduced accordingly.

5.2. Research Suggestions. According to the research situation of this paper, some investment suggestions are given. Because the negative news events studied in this paper are only a small part of the influencing factors of stock price fluctuation and cannot represent the whole situation, the suggestions given in this paper are only for reference.

First, if we want to obtain excess return during the period of negative news of listed companies, we should change to "sensitive" investors, get relevant information in time, and respond sensitively. We should try our best to use professional investment knowledge to predict the type of negative news and predict its possible impact and strive to make a correct judgment. We should reduce blind following, listen to the advice of professional investment experts, keep calm at any time, and avoid the occurrence of panic that leads to wrong decision making.

Second, in terms of trading timing, after careful analysis of the future trend of the stock price of listed companies, we should try our best to buy or sell at an appropriate time. In the research results of this paper, the period from the previous trading day to the following four trading days of negative news is the most active period of stock price fluctuation. During this period, for some stocks, the lowest price will appear at any time. In the spirit of buying low and selling high, we should try our best to buy when the stock price falls and sell as soon as possible when the stock price rises to earn the price difference. After the negative news event occurs, the stock price fluctuates from high to low. We should pay attention to the trend of the stock price at any time and make corresponding adjustments to the investment decision.

Third, which stocks should continue to be held? According to the research results of this paper, the stocks of listed companies with good performance should continue to be held. When negative news events occur, investors should analyze whether the return on shareholders' equity and earnings per share of listed companies are high. If the company's performance is good and the profitability is strong for a long time in the past, it should continue holding the stocks of this kind of listed companies because although such companies have temporary negative news events, it may have a certain impact in the short term. The loss of continuing to hold stocks may be less than that of timely selling off the stocks held. Moreover, from the long-term perspective of investment, companies with good profits will continue to increase the excess return on investment. Why not? In addition, we can also follow the investment trend of 
large shareholders, but this does not guarantee the correct decision making because according to the research results of this paper, not all the major shareholders of tradable shares make the same decisions, and they may offset each other and eventually fail to obtain excess returns.

The sudden negative news of listed companies, to a certain extent, will also affect the company's reputation, thus affecting its daily operation. Therefore, the listed enterprises should improve their own crisis management awareness and strengthen preventive measures and coping with the crisis, so as to minimize the harm of the crisis to enterprises. Secondly, they should do a good job in dealing with the aftermath of the crisis, be good at summarizing and evaluating the report results of crisis handling, and timely correct the problems found in the summary and evaluation. In the future, we should try our best to conduct some public welfare activities which are conducive to restoring the company's reputation and increase investors' confidence in the listed companies.

\section{Data Availability}

The data used in this paper were obtained from different sources (Hexun, Netease, Sina News, Fenghuang finance, and other websites, respectively).

\section{Conflicts of Interest}

The authors declare that there are no conflicts of interest.

\section{References}

[1] P. K. Narayan, "Can stale oil price news predict stock returns?" Energy Economics, vol. 83, pp. 430-444, 2019.

[2] R. P. Schumaker and N. Maida, "Analysis of stock price movement following financial news article release," Communications of the IIMA, vol. 16, no. 1, 2018.

[3] Y. Y. Wei, "Research on negative reports and their communication effects," Master's thesis on Journalism, Zhengzhou University, 2005.

[4] S. Q. He, "Negative news (negative report) problem research," Master's thesis of Journalism, Jinan University, 2008.

[5] Q. Bai and X. Y. Chen, Negative News and Related Concepts, Nanjing Social Sciences, vol. 1, pp. 130-136, 2010.

[6] A. Rose, "Rumor in the stock market," Public Opinion Quarterly, vol. 15, no. 3, pp. 461-486, 1951.

[7] V. Niederhoffer, "The analysis of world events and stock prices," The Journal of Finance, vol. 44, pp. 193-219, 1971.

[8] P. Klibanoff, "Investor reaction to salient news in closed end country funds," The Journal of Finance, vol. 53, pp. 673-699, 1998.

[9] F. Takeda and H. Yamazaki, "Stock price reactions to public TV programs on listed Japanese companies," Economics Bulletin, vol. 13, pp. 1-7, 2006.

[10] P. L. Davies and M. Canes, "Stock prices and the publication of second-hand information," Journal of Business, vol. 51, no. 1, pp. 43-56, 1978.

[11] S. D. Smith and A. A. Syed, "Stock price reactions to the wall street journal's securities recommendations," Journal of Financial and Quantitative Analysis, vol. 25, no. 3, pp. 399-410, 1990.
[12] H. Kiymaz, "The effects of stock market rumors on stock prices: evidence from an emerging market," Journal of Multinational Financial Management, vol. 11, pp. 105-115, 2001.

[13] W. S. Chan and Wesley, "Stock price reaction to news and nonews: drift and reversal after headlines," Journal of Financial Economics, vol. 70, no. 2, pp. 223-260, 2003.

[14] M. Baker and J. C. Stein, "Market liquidity as a sentiment indicator," Journal of Financial Markets, vol. 7, no. 3, pp. 271-299, 2004.

[15] M. Seasholes and G. Wu, "Predictable behavior, profits, and attention," Journal of Empirical Finance, vol. 14, pp. 590-610, 2007.

[16] P. C. Tetlock, "Giving content to investor sentiment: the role of media in the stock market," The Journal of Finance, vol. 62, pp. 1139-1168, 2007.

[17] P. C. Tetlock and M. Saar-tsechansky, "More than words: quantifying language to measure firm's fundamentals," The Journal of Finance, vol. 63, pp. 1437-1467, 2008.

[18] L. Catania and T. Proietti, "Forecasting volatility with timevarying leverage and volatility of volatility effects," International Journal of Forecasting, vol. 36, no. 4, pp. 1301-1317, 2020.

[19] M. Otaify, "Modeling volatility of size, value and financial leverage-sorted portfolios: evidence from Egyptian stock exchange," Journal of Public Affairs, vol. 2020, no. 9, pp. 1-16, 2020.

[20] X. Deng, "Negative public opinion, stock price changes and public opinion response measures," Statistics and information forum, vol. 30, no. 11, pp. 78-83, 2015.

[21] H. Liu, X. G. Zhou, and G. Li, “An empirical analysis of the influence of hearsay news on the shares of listed companies in China," Wuhan finance, vol. 9, pp. 16-19, 2003.

[22] J. Zhu, "Research on the correlation between Internet public opinion and stock price of listed companies," Tax Economy Research, vol. 1, pp. 85-96, 2015.

[23] Q. C. Shi and L. Y. Xu, "An empirical study on the impact of negative public opinion on the stock price fluctuation of listed companies," vol. 10, pp. 54-62, 2014.

[24] Y. L. Xue, Z. J. Yu, and J. Yang, "Negative media reports and stock market performance are based on the analysis of Shuanghui clenbuterol event," Technology and Companies, vol. 10, pp. 5-6, 2014.

[25] Y. L. Rao, D. F. Peng, and D. C. Cheng, "Does media attention affect abnormal returns of stocks?: empirical data from Chinese stock market," Theory and practice of systems engineering, vol. 30, no. 2, pp. 287-297, 2010.

[26] E. F. Fama, "The behavior of stock-market prices," Journal of Business, vol. 38, no. 1, pp. 34-105, 1965.

[27] Y. Ren, "Research on the impact of environmental events on the stock prices of listed enterprises in China: taking Zijin mining pollution incident as an example," Master's thesis of enterprise management, East China Normal University, 2012.

[28] H. W. Chen and X. M. Chen, "Event response of stock prices: method background and application based on Chinese stock market," Economic Research, vol. 1, pp. 40-47, 2002.

[29] X. Y. Chen and F. Jiang, "Test power of event simulation and abnormal return model: empirical test Based on China's a-share market," Accounting Research, vol. 7, pp. 25-31, 2005.

[30] N. Zhang and W. B. Shen, "Investor response to negative news reports: an empirical study from the perspective of investor sentiment," Management Modernization, vol. 36, no. 4, pp. 16-19, 2016.

[31] W. F. M. De Bondt, "A portrait of the individual investor," European Economic Review, vol. 42, no. 3, pp. 831-844, 1998. 
[32] W. F. M. De Bondt, "A portrait of the individual investor," European Economic Review, vol. 42, no. 3-5, pp. 831-844, 1998.

[33] B. Qi, M. Huang, and Z. S. Chen, "Institutional investors and stock market volatility," Financial research, vol. 9, pp. 54-64, 2006.

[34] J. He, J. B. He, X. H. Wang, and L. Wei, "Can institutional investors stabilize the stock market?-empirical evidence from China," Managing world, vol. 8, pp. 35-42, 2007.

[35] P. Tao and X. W. Liu, "Impact of foreign emergencies on domestic stock market," Prediction, vol. 34, no. 2, pp. 66-70, 2015.

[36] S. Asthana, S. Balsam, and J. Krishnan, Audit Firm Reputation and Client Stock Price Reactions: Evidence from the Enron Experience, Social Science Electronic Publishing, Rochester, NY, USA, 2003.

[37] S. S. Zhao, "Analysis and evaluation of influencing factors on goodness of fit R square," Journal of Northeast University of Finance and Economics, vol. 2003, no. 3, pp. 56-58, 2003.

[38] D. M. Cutler, "What moves stock prices?" Journal of Portfolio Management, vol. 3, pp. 48-56, 1998. 